\title{
Treatment of Cholesterol Embolism With Corticosteroids and Alprostadil
}

\author{
Seung Mook Jung \\ Department of Internal Medicine, Gimpowoori Hospital, Gimpo, Korea
}

Corresponding Author:

Seung Mook Jung, MD

https://orcid.org/0000-0001-6071-8055

Department of Internal Medicine,

Gimpowoori Hospital, 11 Gamam-ro,

Gimpo 10099, Korea

E-mail: jsms67@naver.com

Received: November 19, 2018

Revised: December 28, 2018

Accepted: January 27, 2019

\begin{abstract}
Cholesterol embolism is a rare but serious disease that can lead to chronic renal failure or death. Despite the recent increase in the incidence of this disease, there is no consensus on the optimal treatment modality. Supportive care is usually the mainstay of treatment. We report a case of cholesterol embolism after renal artery stenting that was successfully treated with corticosteroids and alprostadil. (Ann Geriatr Med Res 2019;23:31-34)
\end{abstract}

Key Words: Cholesterol embolism, Corticosteroids, Alprostadil

\section{INTRODUCTION}

Cholesterol embolism is a rare but serious disease that may occur following invasive endovascular procedures. Although it was first reported by Fenger et al. ${ }^{1)}$ in 1844 , there is still no consensus on its definitive treatment. Treatment of cholesterol embolism with anti-inflammatory agents, including corticosteroids, has been reported, ${ }^{2-4)}$ but the treatment results have been varied and often disappointing. Therefore, the main treatment modality continues to be supportive treatment, which generally comprises fluid supplementation, blood pressure control, and nutritional and metabolic support. ${ }^{5)}$ We reported a case of cholesterol embolism following renal artery stenting that was successfully treated with a combination of corticosteroids and alprostadil.

\section{CASE REPORT}

A 63-year-old man presented with headache and sudden blood pressure elevation. Although he reported taking blood pressure medications after being diagnosed with hypertension, he showed a sudden increase in blood pressure. At presentation, his blood pressure was 200/110 mmHg. Abdominal computed tomography performed to assess whether secondary hypertension was the cause of sudden blood pressure elevation revealed severe stenosis of both renal arteries (Fig. 1).

The patient was admitted and was scheduled to undergo stenting of both renal arteries. At admission, his serum creatinine $(\mathrm{Cr})$ level and blood pressure were $1.31 \mathrm{mg} / \mathrm{dL}$ and 150/90 $\mathrm{mmHg}$, respectively. We prescribed aspirin (100 mg), clopidogrel (75 mg), pitavastatin (4 mg), and nifedipine (30 mg). Renal artery stenting was successfully performed over 2 days, and he was discharged 3 days later (Fig. 1). At discharge, he had no other complications. His blood pressure was 140/90 $\mathrm{mmHg}$, and laboratory findings indicated that he had a $\mathrm{Cr}$ level of $1.3 \mathrm{mg} / \mathrm{dL}$ and no eosinophilia.

Fifteen days post-discharge, the patient presented with general myalgia and mild fever. He had developed mottled purple discoloration and pain in his feet. Moreover, the fifth toe of his right foot showed findings indicative of necrosis (Fig. 2). Thus, the patient was diagnosed with cholesterol embolism and was re-admitted.

The following laboratory findings were noted at readmission: serum $\mathrm{Cr}$ level, $2 \mathrm{mg} / \mathrm{dL}$; hemoglobin concentration, $11.6 \mathrm{~g} / \mathrm{dL}$; and eosinophil level, 16\%. His body temperature was $37.6^{\circ} \mathrm{C}$. We provided supportive care comprising hydration, blood pressure control, and statins. We reviewed existing reports and planned to administer high doses of corticosteroids and alprostadil. Initially, we prescribed methylprednisolone $(250 \mathrm{mg}$ ) and alprostadil (100 mg). After 5 days, the methylprednisolone dose was reduced to $125 \mathrm{mg}$. Four days after treatment initiation, his foot pain was alleviated, and the color of his feet also improved. Twelve days after readmission, he developed upper gastrointestinal bleeding and a mild cerebral infarction. Both conditions improved without serious deterioration or sequelae. Corticosteroids were discontinued due to gastrointestinal bleeding, and $100 \mathrm{mg}$ of alprostadil alone was continued.

The patient recovered without further deterioration and was discharged 24 days after readmission. At discharge, his foot pain had subsided. The necrosis had healed, and the purple discoloration in his toes had reduced (Fig. 3). 

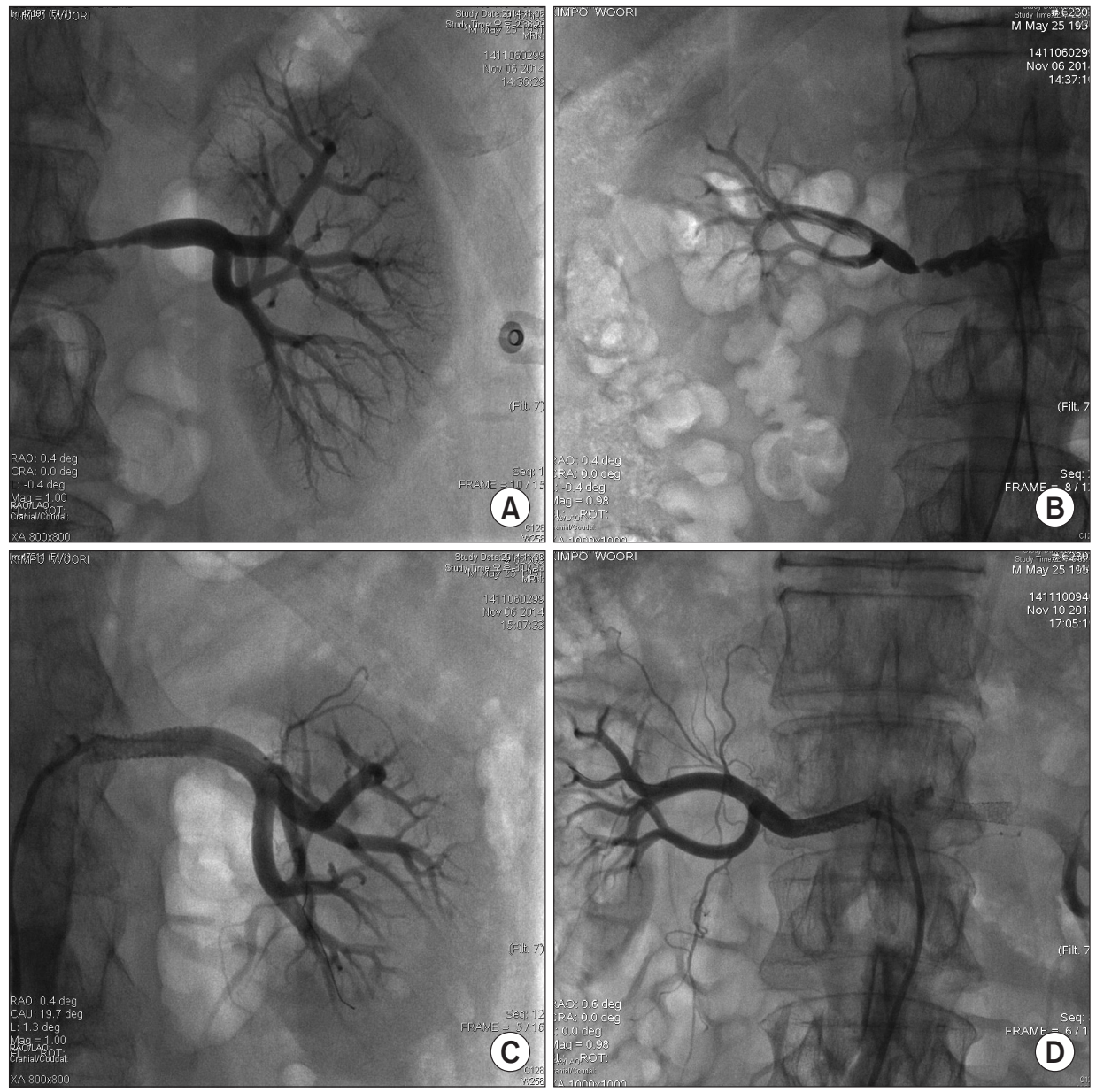

Fig. 1. Angiography of both renal arteries pre (A, B) and post angioplasty (C, D).

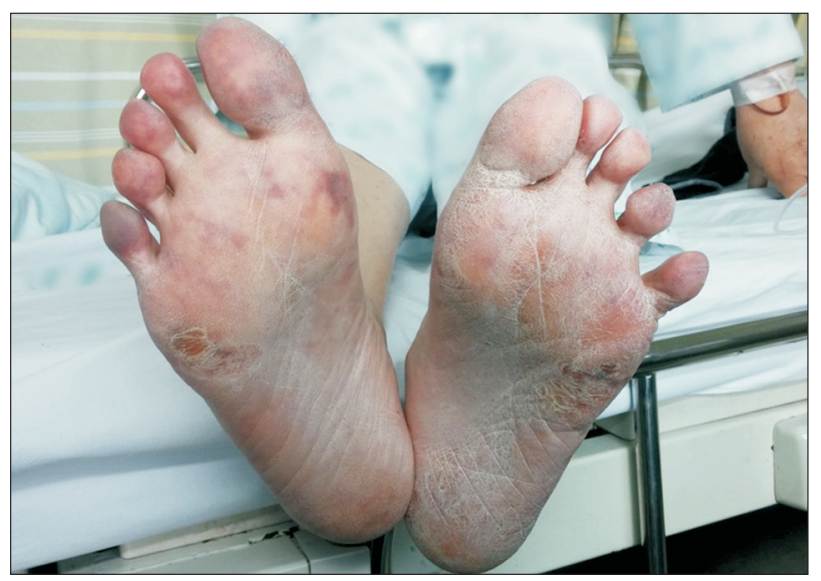

Fig. 2. Blue toes on both feet at readmission.

Laboratory examination revealed a $\mathrm{Cr}$ level of $1.54 \mathrm{mg} /$ $\mathrm{dL}$, hemoglobin concentration of $9.9 \mathrm{~g} / \mathrm{dL}$, and eosinophil level of $4.8 \%$.

Four years later, the patient remains well and his condition shows no signs of worsening.

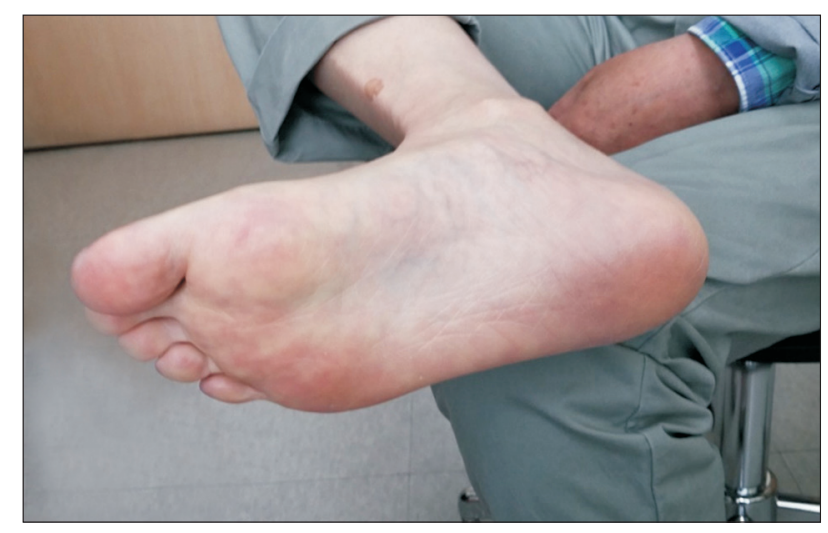

Fig. 3. Recovery of blue toes and necrosis.

\section{DISCUSSION}

Cholesterol embolism is a rare but serious systemic disease. It may occur spontaneously, but it usually occurs after invasive endovascular procedures in patients with advanced atherosclerosis. The incidence of cholesterol embolism has been reported to be $0.09 \%-1.4 \%$ in patients undergoing invasive endovascular procedures, such as cardiac catheterization and renal artery stenting. Its incidence 
has been increasing with the increasing use of invasive endovascular techniques. ${ }^{6,7)}$ Cholesterol embolism involves rupturing of the atherosclerotic plaques of proximal largecaliber arteries; this results in embolization of the plaque debris, which includes cholesterol crystals, into the distal arterioles and capillaries. These crystals mechanically occlude arterioles that are $100-200 \mu \mathrm{m}$ in diameter, which triggers a secondary inflammatory response. Infiltration of polymorphonuclear leukocytes and eosinophils, as a result of inflammatory reactions against the foreign body, occurs during the acute phase. Then, mononuclear cells appear and become giant cells that phagocytize the cholesterol crystals. Vascular spasm and intraluminal thrombus formation also occur. Inflammatory vascular changes advance with further disease progression. Endothelial proliferation and intimal fibrosis lead to narrowing or even obliteration of the arterial lumen, eventually resulting in tissue ischemia and failure. ${ }^{8)}$ Based on this pathophysiology, aggressive anti-inflammatory therapy and use of vasodilators may be helpful.

Corticosteroids are powerful anti-inflammatory and immuno-suppressive agents that are thought to play a role in in-filtration of inflammatory cells and in prevention of cell proliferation and fibrosis. However, treatment of cholesterol embolism with steroids has shown varying results. Early reports did not show significant benefits with this treatment. ${ }^{9,10)}$ However, recent reports have shown effective improvement. ${ }^{11,12)}$ These differences may be related to the timing of drug use or disease severity. The optimal dose and duration of corticosteroid treatment have not yet been determined. Various treatment methods have been reported, such as administration of low-dose steroids and high-dose pulse therapy. High-dose pulse therapy has been shown to be highly effective in recovering renal function. ${ }^{11,12)}$ Therefore, we administered high-dose pulse therapy with $250 \mathrm{mg}$ methylprednisolone for 5 days, followed by $125 \mathrm{mg}$ methylprednisolone for 9 days. In our case, this treatment was effective in preventing deterioration of renal function and in improving the mottled purple discoloration in the patient's feet. However, long-term use of steroids requires caution, because it may cause endocrine abnormalities, such as diabetes, or infections due to decreased immunity. Therefore, it may be appropriate to stop steroid administration or to administer small maintenance doses after short-term use in the acute phase.

Combination therapy with other anti-inflammatory agents may increase effectiveness of treatment; however, this strategy may further exacerbate the risk of infection due to immunodeficiency. In this respect, prostaglandin $\mathrm{E}_{1}$ $\left(P G E_{1}\right)$ is a drug that can be used safely and is also effective in treating cholesterol embolism. PG $\mathrm{E}_{1}$ has vasodilating activity, resulting in the inhibition of platelet aggregation and modulation of cell proliferation. ${ }^{13)} \mathrm{PG} \mathrm{E}_{1}$ has also been reported to have a positive effect on renal function. ${ }^{14)}$ Combination therapy with corticosteroids and alprostadil may be more effective than monotherapy.
Currently, no treatment is available for direct removal of cholesterol crystals that cause mechanical occlusion. Therefore, the goal of treatment is to minimize the secondary inflammatory response that triggers the foreign body reaction against crystals and to prevent irreversible damage to target organs. Therefore, treatment for inflammatory reactions should be initiated as soon as possible. Currently, no treatment is available for irreversible damage.

A consensus has not yet been reached in regard to the optimal treatment for cholesterol embolism. However, strong anti-inflammatory agents may have a beneficial effect during acute-phase inflammatory reactions. Therefore, administration of a combination of steroids and alprostadil may be a good option for improving treatment success rates.

\section{CONFLICTS OF INTEREST DISCLOSURES}

The researcher claims no conflicts of interest.

\section{REFERENCES}

1. Fenger CE, Jacobsen JP, Dahlerup EA, Hornemann E, Collin T. Beretning af obductionen over Albert Thorvaldsen (autopsy report of Albert Thorvaldsen). Ugeskr Laeger 1844;10:215-8.

2. Fine MJ, Kapoor W, Falanga V. Cholesterol crystal embolization: a review of 221 cases in the English literature. Angiology 1987;38:769-84.

3. Nakayama M, Izumaru K, Nagata M, Ikeda H, Nishida K, Hasegawa $\mathrm{E}$, et al. The effect of low-dose corticosteroids on short- and long-term renal outcome in patients with cholesterol crystal embolism. Ren Fail 2011;33:298-306.

4. Masuda J, Tanigawa T, Nakamori S, Sawai T, Murata T, Ishikawa E, et al. Use of corticosteroids in the treatment of cholesterol crystal embolism after cardiac catheterization: a report of four Japanese cases. Intern Med 2013;52:993-8.

5. Belenfant X, Meyrier A, Jacquot C. Supportive treatment improves survival in multivisceral cholesterol crystal embolism. Am J Kidney Dis 1999;33:840-50.

6. Scolari F, Tardanico R, Zani R, Pola A, Viola BF, Movilli E, et al. Cholesterol crystal embolism: a recognizable cause of renal disease. Am J Kidney Dis 2000;36:1089-109.

7. Fukumoto Y, Tsutsui H, Tsuchihashi M, Masumoto A, Takeshita A; Cholesterol Embolism Study (CHEST) Investigators. The incidence and risk factors of cholesterol embolization syndrome, a complication of cardiac catheterization: a prospective study. J Am Coll Cardiol 2003;42:211-6.

8. Kronzon I, Saric M. Cholesterol embolization syndrome. Circulation 2010;122:631-41.

9. Kaufman JL, Stark K, Brolin RE. Disseminated atheroembolism from extensive degenerative atherosclerosis of the aorta. Surgery 1987;102:63-70.

10. Colt HG, Begg RJ, Saporito JJ, Cooper WM, Shapiro AP. Cholesterol emboli after cardiac catheterization. Eight cases and a review of the literature. Medicine (Baltimore) 1988;67:389-400.

11. Mann SJ, Sos TA. Treatment of atheroembolization with cortico- 
steroids. Am J Hypertens 2001;14:831-4.

12. Graziani G, Santostasi S, Angelini C, Badalamenti S. Corticosteroids in cholesterol emboli syndrome. Nephron 2001;87:371-3.

13. Moreschi D Jr, Fagundes DJ, Amado LEB, Hernandes L, Moreschi HK. [Effects of prostaglandin E1 (PGE1) in the genesis of blood capillaries in rat ischemic skeletal muscle: histological study]. J Vasc Bras 2007;6:316-24. Portuguese.

14. Minatohara K. Renal failure associated with blue toe syndrome: effective treatment with intravenous prostaglandin E-1. Acta Derm Venereol 2006;86:364-5. 